BRIEF COMMUNICATION

\title{
Sulfate adenylyl transferase kinetics and mechanisms of metabolic inhibitors of microbial sulfate respiration
}

\author{
Hans K. Carlson (iD) ${ }^{1,2}$, Matthew D. Youngblut ${ }^{1,4}$, Steven A. Redford (D) ${ }^{1,5}$, Adam J. Williamson ${ }^{1,6}$ and John D. Coates (D) ${ }^{1,3}$
}

(c) The Author(s) 2021

Sulfate analog oxyanions that function as selective metabolic inhibitors of dissimilatory sulfate reducing microorganisms (SRM) are widely used in ecological studies and industrial applications. As such, it is important to understand the mode of action and mechanisms of tolerance or adaptation to these compounds. Different oxyanions vary widely in their inhibitory potency and mechanism of inhibition, but current evidence suggests that the sulfate adenylyl transferase/ATP sulfurylase (Sat) enzyme is an important target. We heterologously expressed and purified the Sat from the model SRM, Desulfovibrio alaskensis G20. With this enzyme we determined the turnover kinetics $\left(k_{\mathrm{cat}}, K_{\mathrm{M}}\right)$ for alternative substrates (molybdate, selenate, arsenate, monofluorophosphate, and chromate) and inhibition constants $\left(K_{l}\right)$ for competitive inhibitors (perchlorate, chlorate, and nitrate). These measurements enable the first quantitative comparisons of these compounds as substrates or inhibitors of a purified Sat from a respiratory sulfate reducer. We compare predicted half-maximal inhibitory concentrations $\left(\mathrm{IC}_{50}\right)$ based on Sat kinetics with measured $\mathrm{IC}_{50}$ values against $D$. alaskensis $\mathrm{G} 20$ growth and discuss our results in light of known mechanisms of sensitivity or resistance to oxyanions. This analysis helps with the interpretation of recent adaptive laboratory evolution studies and illustrates the value of interpreting gene-microbe-environment interactions through the lens of enzyme kinetics.

ISME Communications; https://doi.org/10.1038/s43705-021-00069-1

Selective inhibitors of dissimilatory sulfate reducing microorganisms (SRM) are both valuable tools for ecological studies and treatment strategies to abrogate unwanted sulfide production in industrial systems [1, 2]. The best studied selective SRM inhibitors are the inorganic oxyanion sulfate analogs including molybdate, tungstate, selenate, chromate, monofluorophosphate, arsenate, nitrate, perchlorate, and chlorate [3-6]. Remarkably, although direct interaction with the sulfate activating enzyme, sulfate adenylyl transferase (Sat) has been implicated as a primary mode of action for these compounds [3, 7], there is little kinetic data for these sulfate analogs as substrates or inhibitors of purified Sat enzymes from respiratory SRM. Other mechanisms of toxicity, tolerance and adaptation have been implicated for oxyanions against model SRM including competition for sulfate uptake [8, 9], ATP consuming futile cycles $[10,11]$ and detoxification via enzymatic reduction and efflux $[5,12]$.

We heterologously expressed, purified and kinetically characterized the Sat from the model SRM, Desulfovibrio alaskensis G20 as reported previously [13]. Briefly, the Sat was expressed in E. coli and purified using a combination of affinity chromatography and ion exchange chromatography. Substrate kinetic parameters were measured by monitoring pyrophosphate accumulation using a modified molybdenum blue assay. Alongside our previous measurements with molybdate [13], we report kinetic parameters for four other alternative substrates including selenate, arsenate, monofluorophosphate, and chromate [13-15] (Table 1A). Previously we found that perchlorate is a competitive inhibitor of the Sat [13], and we now report inhibition constants $\left(K_{\mathrm{l}}\right)$ for the other competitive inhibitors nitrate and chlorate, both of which are competitive with the oxyanion substrate, molybdate, used in our assays but not competitive with the Sat co-substrate, ATP (Table 1B).

While this set of sulfate analogs has previously been inferred to target Sat based on their selective influence on SRM metabolic activity and growth [4, 5, 7, 10], cell lysate enzyme assays [3], genetic screens $[7,16]$ and induction of the sulfate reduction regulon [7] our results with the purified enzyme enable the first quantitative ranking of these compounds as substrates or inhibitors of Sat. It is striking that the relative affinities $\left(K_{\mathrm{M}}\right.$ and $K_{\mathrm{l}}$ ) of these oxyanions vary by over an order of magnitude given their similar geometries and formal charges (Table 1). The highest affinity substrate is arsenate $\left(K_{\mathrm{M}}=0.0617 \pm 0.026\right)$ while the lowest affinity substrate is molybdate $\left(K_{\mathrm{M}}=3.26 \pm 0.55\right)$. The highest affinity inhibitor is perchlorate $\left(K_{\mathrm{l}}=0.138 \pm 0.014\right)$ while the lowest affinity inhibitor is nitrate $\left(K_{1}=3.60 \pm 0.27\right)$.

The potency of a competitive substrate or inhibitor against cellular growth is determined by the affinity of the inhibitor for its primary target and detoxification reactions. For cytoplasmic enzymes, mechanisms of transport and efflux are important to consider. Thus, we can compare the measured affinities against

\footnotetext{
${ }^{1}$ Energy \& Biosciences Institute, University of California, Berkeley, Berkeley, CA 94720, USA. ${ }^{2}$ Environmental Genomics and Systems Biology, Lawrence Berkeley National Lab, 1 Cyclotron Road, Berkeley, CA 94704, USA. ${ }^{3}$ Department of Plant and Microbial Biology, University of California, Berkeley, Berkeley, CA 94720, USA. ${ }^{4}$ Present address: Twist Bioscience, 681 Gateway Blvd, South San Francisco, CA 94080, USA. ${ }^{5}$ Present address: Graduate Program in Biophysical Sciences, The University of Chicago, Chicago, IL, USA. ${ }^{6}$ Present address: CENBG, Université de Bordeaux, CNRS-IN2P3/, 19 Chemin du Solarium, CS10120, 33175 Gradignan, France. ${ }^{凶}$ email: hkcarlson@lbl.gov
} 
Table 1. Kinetic parameters for $D$. alaskensis $\mathrm{G} 20$ sulfate adenylyl transferase (Sat).

\begin{tabular}{|c|c|c|c|c|}
\hline \multicolumn{5}{|l|}{ A. } \\
\hline Substrate & $k_{\text {cat }}\left(s^{-1}\right)$ & $K_{M}(\mathrm{mM})$ & $\begin{array}{l}k_{\text {cat }} / K_{M}\left(M^{-1}\right. \\
\left.s^{-1}\right)\end{array}$ & Reference \\
\hline $\mathrm{MoO}_{4}{ }^{2-}$ & $14.5 \pm 1.2$ & $3.26 \pm 0.55$ & $4.4 \times 10^{3}$ & 13 \\
\hline $\mathrm{SeO}_{4}{ }^{2-}$ & $0.284 \pm 0.032$ & $1.77 \pm 0.55$ & $1.6 \times 10^{2}$ & This work \\
\hline $\mathrm{FPO}_{4}{ }^{2-}$ & $11.0 \pm 1.6$ & $1.44 \pm 0.56$ & $7.6 \times 10^{3}$ & This work \\
\hline $\mathrm{AsO}_{4}{ }^{3-}$ & $3.88 \pm 0.32$ & $0.0617 \pm 0.026$ & $6.3 \times 10^{4}$ & This work \\
\hline $\mathrm{CrO}_{4}{ }^{2-}$ & $16.0 \pm 0.79$ & $0.793 \pm 0.14$ & $2.0 \times 10^{4}$ & This work \\
\hline \multicolumn{5}{|l|}{ B. } \\
\hline Inhibitor & $\begin{array}{l}K_{1}-\text { Varied } \\
\mathrm{MoO}_{4}^{2-}(\mathrm{mM})\end{array}$ & $\begin{array}{l}K_{1}-\text { Varied } \\
\text { ATP }(\mathrm{mM})\end{array}$ & $\begin{array}{l}\text { Average } \\
K_{\mathrm{I}}(\mathrm{mM})\end{array}$ & Reference \\
\hline $\mathrm{ClO}_{3}^{-}$ & $0.316 \pm 0.017$ & $1.45 \pm 0.076$ & 0.833 & This work \\
\hline $\mathrm{NO}_{3}{ }^{-}$ & $3.60 \pm 0.27$ & $12.5 \pm 0.98$ & 8.05 & This work \\
\hline $\mathrm{ClO}_{4}^{-}$ & $0.138 \pm 0.014$ & $0.915 \pm 0.15$ & 0.5265 & 13 \\
\hline
\end{tabular}

Sat with known inhibitory potencies of these oxyanions against growth of D. alaskensis G20 [5] to infer the extent to which Sat is a primary target of these oxyanions and the magnitude of other processes that influence intracellular inhibitor concentration or other modes of toxicity. While inhibitor $K_{\mathrm{I}}$ or $K_{\mathrm{M}}$ is independent of the substrate concentration, enzyme $I C_{50}$ increases at higher substrate concentrations for competitive substrates and inhibitors (Eq. 1) [17].

$$
\mathrm{IC}_{50} \mathrm{~K}_{\mathrm{l}}\left(1+\left([\text { substate }] / \mathrm{K}_{\mathrm{M}}\right)\right)
$$

Thus, from measurements of sulfate $K_{\mathrm{M}}$ and competitive inhibitor $K_{\mathrm{I}}$ or competitive substrate $K_{\mathrm{M}}$, we can estimate the competitive substrate/inhibitor $I C_{50}$ against Sat for a given concentration of sulfate (Fig. 1). The predicted IC50s can be compared against measured IC50s from previous replicate dose-response assays against the growth of G20 in liquid culture [5]. To model $I_{50} S$ we use a sulfate $K_{M}$ of $2.93 \pm 0.26 \mathrm{mM}$ empirically determined for a homologous Desulfovibrio Sat [18]. The homologous Sat is $81 \%$ identical to the G20 Sat, and molybdate $K_{\mathrm{M}}$ values only vary between $1 \mathrm{mM}$ and $3 \mathrm{mM}$ for different Desulfovibrio [19]. Thus, this is likely a reasonable approximation for the $\mathrm{G} 20$ Sat $K_{\mathrm{M}}$. Because we do not know the cytoplasmic concentrations of sulfate during batch growth in the presence of these inhibitors we calculated Sat $I_{50} \mathrm{~S}$ at three concentrations of sulfate including: $15 \mathrm{mM}$ sulfate (the mean extracellular concentration in $G 20$ batch cultures $[5,9,12,13,20]$ ), $5 \mathrm{mM}$ sulfate (the mean intracellular sulfate concentration in typical G20 batch cultures [21]), and $0.15 \mathrm{mM}$ sulfate (which is close to the lowest intracellular concentration measured in G20 batch cultures [21] and an order of magnitude lower than the Sat sulfate $K_{\mathrm{M}}$ ).

For the Sat substrates molybdate, selenate and monofluorophosphate, the predicted Sat $\mathrm{IC}_{50} \mathrm{~S}$ are higher than the measured growth $I C_{50} \mathrm{~S}$. As such, the measured $I C_{50} \mathrm{~S}$ must reflect an additional mode of growth inhibition apart from activity as competitive substrates of Sat or bioconcentration via uptake with minimal efflux of the inhibitor in the G20 cytoplasm. Molybdate and selenate form unstable APS analogs as products of Sat catalyzed reactions which rapidly decompose [22, 23]. This drives a non-productive, "futile" cycle which leads to rapid ATP hydrolysis and is thought to be a major mode of cellular toxicity of these compounds [10]. Selenate and molybdate are also competitive with sulfate uptake [8] and, at least in $D$. vulgaris Hildenborough, an additional protein aside from Sat may catalyze non-productive adenosine $5^{\prime}$-phosphomolybdate

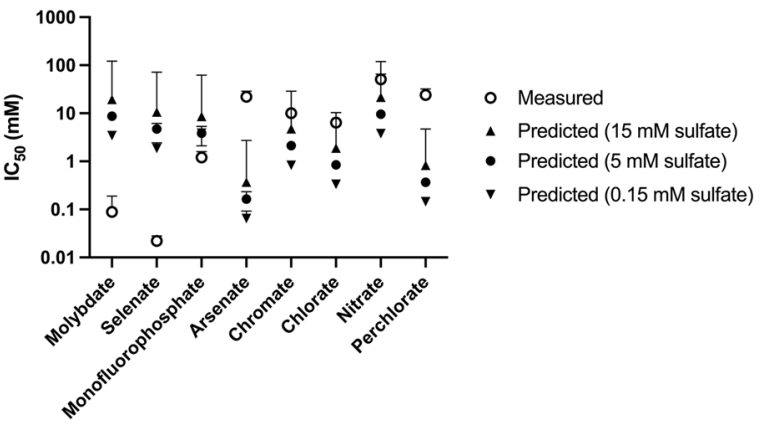

Fig. 1 Measured and predicted $I_{50}$ values for $D$. alaskensis G20 Sat. Measured $\mathrm{IC}_{50} \mathrm{~S}$ are from Reference [5] and error bars represent the $95 \%$ confidence intervals of replicate dose-response fits. Predicted $\mathrm{IC}_{50} \mathrm{~S}$ are based on measured kinetic parameters for for the G20 sulfate adenyl transferase (Table 1) using Eq. (1) and calculated using for intracellular sulfate concentrations of $15 \mathrm{mM}$ (closed upright triangles) $5 \mathrm{mM}$ (closed circles), and $0.15 \mathrm{mM}$ (closed inverted triangles). Predicted $\mathrm{IC}_{50} \mathrm{~s}$ error bars are upper and lower bounds calculated based on error in Sat kinetic measurements range (this work, References $[13,18]$ ).

formation and ATP hydrolysis, but it is unknown if similar proteins are in D. alaskensis G20 [11]. Monofluorophosphate reacts with ATP at the Sat as a dead-end substrate to form the stable product adenosine $5^{\prime}$-(2- fluorodiphosphate), ADP $\beta F$ [24], so ATP consumption through futile cycling is not a likely mechanism of cellular inhibition. Fluoride ion $\left(\mathrm{F}^{-}\right)$toxicity may contribute to the monofluorophosphate mechanism of action, but this is ameliorated by a fluoride efflux pump [5].

The other divalent oxyanions in our panel, arsenate and chromate, are less inhibitory to $D$. alaskensis $G 20$ growth than predicted based on the Sat $I C_{50}$. Arsenate is the highest affinity Sat substrate from our panel with a Sat $K_{\mathrm{M}}$ 50-100-fold lower than molybdate or selenate (Table 1, Fig. 1A). The measured arsenate $\mathrm{IC}_{50}$ against $\mathrm{G} 20$ growth is $\sim 10$-fold higher than the predicted Sat arsenate $\mathrm{IC}_{50}$ and $\sim 100$-fold higher than the measured molybdate or selenate growth $\mathrm{IC}_{50} \mathrm{~s}$. However, arsenate is known to be catalytically reduced and effluxed by $\mathrm{G} 20$ and deletion of the arsenate reductase and efflux systems renders G20 10-fold more sensitive to arsenate [12]. Arsenate also reacts abiotically with sulfide [25]. These observations are consistent with the difference the measured arsenate $\mathrm{IC}_{50}$ being lower than predicted (Fig. 1). Chromate is the second highest affinity Sat substrate in our panel, and the predicted $\mathrm{IC}_{50}$ is slightly lower than the measured $I C_{50}$. Chromate is catalytically reduced by G20 [26] and reacts abiotically with sulfide [27] which will increase the effective concentration required to inhibit Sat. Taken together, our results are consistent with Sat being an important target of both arsenate and chromate in G20, and this is consistent with the previous observation that both of these compounds are selective inhibitors of SRM in marine enrichment cultures [5].

We also compared predicted Sat $\mathrm{IC}_{50} \mathrm{~S}$ with measured growth $I C_{50} S$ for the competitive inhibitors perchlorate, chlorate, and nitrate (Fig. 1). The mechanism of action of these compounds against SRM in complex natural systems is primarily due to biocompetitive exclusion via growth of nitrate or perchlorate respirers and the production of reactive nitrogen and potentially chlorine species $[1,28,29]$. However, at higher concentrations, these oxyanions are direct competitive inhibitors of the sulfate reduction pathway [7]. Understanding the targets and adaptation mechanisms to competitive inhibitors may aid in the development of next-generation small molecule inhibitors that are selective against SRM [30]. 
For nitrate and chlorate, predicted $\mathrm{IC}_{50} \mathrm{~S}$ are less than 10 -fold lower than the measured $I_{50} \mathrm{~S}$ while the predicted perchlorate $I C_{50}$ is nearly 50 -fold lower than the measured $I C_{50}$. Apart from competitive inhibition of Sat, cellular permeability, reactivity and efflux can influence the measured growth $I_{50} \mathrm{~S}$, cytoplasmic reactivity will make cells more sensitive to these compounds through the generation of reactive nitrogen and chlorine species (RNS/RCS). While perchlorate is kinetically very stable, chlorate and nitrate generate cytoplasmic RNS/RCS in G20 [7, 16]. No chlorate or nitrate efflux mechanisms in G20 are known and reduction or these compounds is minimal [7]. Thus, for these compounds it is most likely that measured growth $I_{50} S$ are higher than are expected based on Sat kinetics because oxyanion transport keeps cytoplasmic concentrations of these compounds low.

Indeed, adaptive laboratory evolution and genetics indicate that changes in the permeability of cells to sulfate, nitrate and perchlorate influence sensitivity to these oxyanions. Mutants that increase the expression of sulfate transporters with low perchlorate affinity are implicated in perchlorate resistance [9], and loss of function mutants in putative thiosulfate transporters with high nitrate affinity are implicated in nitrate resistance $[7,16,20]$. Notably, point mutants that alter the activity of sulfate transporters were not observed suggesting that these compounds target a cytoplasmic enzyme, such as Sat, rather than sulfate uptake. In some perchlorate adapted cultures, point mutants in the Sat emerge that alter the $K_{1}$, clearly indicating that Sat is under selection $[9,13]$.

Further characterization of transport kinetics, rates of reduction and efflux, and cytoplasmic concentrations will enable more quantitative predictions of the inhibitory potency and genetic targets of oxyanion inhibitors of sulfate respiration. Nevertheless, our results are consistent with Sat as an important target of these compounds. More generally, comparing the affinities of metabolic inhibitors for transport enzymes versus cytoplasmic metabolic enzymes will be essential for understanding the evolutionary landscapes that microorganisms navigate across environmental gradients of toxicants or nutrients [31-33]. The extent to which cell surface versus cytoplasmic enzymes are under selection depends on enzyme affinities and the relative concentrations of substrates and inhibitors. Thus, enzyme kinetics measurements are critical for understanding genotype-phenotype relationships in complex environments where a bacterial cell is confronted with physicochemically similar substrates and inhibitors such as metal ions, carbon sources or vitamins.

\section{REFERENCES}

1. Liu Y, Engelbrektson A, Stoeva M, Barnum T, Reyes-Umana V, Coates JD. Perchlorate and its application in the oil and gas industry. Oilfield microbiology. 2019. CRC Press, p. 109-28.

2. McGenity TJ. Microbial communities utilizing hydrocarbons and lipids: members, metagenomics and ecophysiology. 2019. Springer, Cham.

3. Peck HD. The ATP-dependent reduction of sulfate with hydrogen in extracts of Desulfovibrio desulfuricans. Proc Natl Acad Sci USA. 1959;45:701-8.

4. Postgate JR. Competitive and non-competitive inhibitors of bacterial sulphate reduction. Microbiology. 1952;6:128-42.

5. Carlson HK, Stoeva MK, Justice NB, Sczesnak A, Mullan MR, Mosqueda LA, et al. Monofluorophosphate is a selective inhibitor of respiratory sulfate-reducing microorganisms. Environ Sci Technol. 2015;49:3727-36.

6. Williamson AJ, Engelbrektson AL, Liu Y, Huang LL, Kumar A, Menon AR, et al. Tungstate control of microbial sulfidogenesis and souring of the engineered environment. Environ Sci Technol. 2020;54:16119-27.

7. Carlson HK, Kuehl JV, Hazra AB, Justice NB, Stoeva MK, Sczesnak A, et al. Mechanisms of direct inhibition of the respiratory sulfate-reduction pathway by (per)chlorate and nitrate. ISME J. 2015;9:1295-305.

8. Cypionka H. Characterization of sulfate transport in Desulfovibrio desulfuricans. Arch Microbiol. 1989;152:237-43.
9. Stoeva MK, Kuehl J, Kazakov AE, Wang O, Rushton-Green R, Coates JD. Anion transport as a target of adaption to perchlorate in sulfate-reducing communities. ISME J. 2020;14:450-62.

10. Taylor BF, Oremland RS. Specific depletion of cellular ATP in Desulfovibrio by molybdate and other Group VI anions. Ann Meet Amer Sot Microbial Abstract Q. 1977:41:268.

11. Zane GM, Wall JD, De Leon KB. Novel mode of molybdate inhibition of Desulfovibrio vulgaris Hildenborough. Front Microbiol. 2020;11:3162.

12. Li X, Krumholz LR. Regulation of arsenate resistance in Desulfovibrio desulfuricans G20 by an arsRBCC operon and an arsC gene. J Bacteriol. 2007;189:3705-11.

13. Mehta-Kolte MG, Stoeva MK, Mehra A, Redford SA, Youngblut MD, Zane G, et al. Adaptation of Desulfovibrio alaskensis G20 to perchlorate, a specific inhibitor of sulfate reduction. Environ Microbiol. 2019;21:1395-406.

14. Gavel OY, Bursakov SA, Calvete JJ, George GN, Moura JJ, Moura I. ATP sulfurylases from sulfate-reducing bacteria of the genus Desulfovibrio. A novel metalloprotein containing cobalt and zinc. Biochemistry. 1998;37:16225-32.

15. He Z, Honeycutt CW. A modified molybdenum blue method for orthophosphate determination suitable for investigating enzymatic hydrolysis of organic phosphates. Commun Soil Sci Plant Anal. 2005;36:1373-83.

16. Korte HL, Fels SR, Christensen GA, Price MN, Kuehl JV, Zane GM, et al. Genetic basis for nitrate resistance in Desulfovibrio strains. Front Microbiol. 2014;5:153.

17. Cheng Y, Prusoff WH. Relationship between the inhibition constant (K1) and the concentration of inhibitor which causes 50 per cent inhibition (150) of an enzymatic reaction. Biochem Pharmacol. 1973;22:3099-108.

18. Kushkevych IV, Antonyak HL, Bartoš M. Kinetic properties of adenosine triphosphate sulfurylase of intestinal sulfate-reducing bacteria. Ukr Biochem J. 2014;86:129-38.

19. Abdulina D, Kováč J, lutynska G, Kushkevych I. ATP sulfurylase activity of sulfatereducing bacteria from various ecotopes. 3 Biotech. 2020;10:55.

20. Wu B, Liu F, Zhou A, Li J, Shu L, Kempher ML, et al. Experimental evolution reveals nitrate tolerance mechanisms in Desulfovibrio vulgaris. ISME J. 2020;14:2862-76.

21. Adkins JF, Orphan VJ, Sessions AL, Sim MS. Quantification and isotopic analysis of intracellular sulfur metabolites in the dissimilatory sulfate reduction pathway. 2016. p. B43D-05.

22. Hanna E, Ng KF, MacRae IJ, Bley CJ, Fisher AJ, Segel IH. Kinetic and stability properties of penicillium chrysogenum atp sulfurylase missing the C-terminal regulatory domain. J Biol Chem. 2004;279:4415-24.

23. Renosto F, Patel HC, Martin RL, Thomassian C, Zimmerman G, Segel IH. ATP sulfurylase from higher plants: kinetic and structural characterization of the chloroplast and cytosol enzymes from spinach leaf. Arch Biochem Biophys. 1993;307:272-85.

24. Satishchandran C, Myers CB, Markham GD. Adenosine-5'-O-(2-fluorodiphosphate) (ADPßF), an analog of adenosine-5'-phosphosulfate. Bioorg Chem. 1992;20:107-14.

25. Rochette EA, Bostick BC, Li G, Fendorf S. Kinetics of arsenate reduction by dissolved sulfide. Environ Sci Technol. 2000;34:4714-20.

26. Li X, Krumholz LR. Thioredoxin is involved in $\mathrm{U}(\mathrm{VI})$ and $\mathrm{Cr}(\mathrm{VI})$ reduction in Desulfovibrio desulfuricans G20. J Bacteriol. 2009.

27. Kim C, Zhou Q, Deng B, Thornton EC, Xu H. Chromium (VI) reduction by hydrogen sulfide in aqueous media: stoichiometry and kinetics. Environ Sci Technol. 2001;35:2219-25.

28. Engelbrektson A, Hubbard CG, Tom LM, Boussina A, Jin YT, Wong H, et al. Inhibition of microbial sulfate reduction in a flow-through column system by (per) chlorate treatment. Front Microbiol. 2014;5:315.

29. Carlson HK, Hubert CRJ. Mechanisms and monitoring of oil reservoir souring control by nitrate or perchlorate injection. In: McGenity TJ (ed). Microbial communities utilizing hydrocarbons and lipids: members, metagenomics and ecophysiology. 2019. Springer International Publishing, Cham, p. 1-25.

30. Carlson HK, Mullan MR, Mosqueda LA, Chen S, Arkin MR, Coates JD. Highthroughput screening to identify potent and specific inhibitors of microbial sulfate reduction. Environ Sci Technol. 2017:51:7278-85.

31. Carlson H, Deutschbauer A, Coates J. Microbial metal resistance and metabolism across dynamic landscapes: high-throughput environmental microbiology. F1000Res. 2017;6.

32. Chandrangsu P, Rensing C, Helmann JD. Metal homeostasis and resistance in bacteria. Nat Rev Microbiol. 2017;15:338-50.

33. Sullivan TS, Gadd GM. Metal bioavailability and the soil microbiome. Adv Agron. 2019;155:79-120.

\section{ACKNOWLEDGEMENTS}

HKC acknowledges funding by ENIGMA, a Scientific Focus Area Program supported by the U. S. Department of Energy, Office of Science, Office of Biological and 
Environmental Research, Genomics: GTL Foundational Science through contract DEAC02-05CH11231 between Lawrence Berkeley National Laboratory and the U. S. Department of Energy. JDC acknowledges funding from the UC Berkeley Energy and Biosciences Institute. The authors would like to thank Magdalena K. Stoeva and Morgan N. Price for critical feedback and suggestions.

\section{AUTHOR CONTRIBUTIONS}

HKC, MDY and JDC conceived of and designed the experiments. MDY, HKC, SAR, AJW conducted experiments. HKC wrote the manuscript. All authors contributed edits on the manuscript.

\section{COMPETING INTERESTS}

JDC declares that he holds IP on the application of (per)chlorate to control souring. The remaining authors declare no conflict of interest.

\section{ADDITIONAL INFORMATION}

Correspondence and requests for materials should be addressed to Hans K. Carlson.

Reprints and permission information is available at http://www.nature.com/ reprints

Publisher's note Springer Nature remains neutral with regard to jurisdictional claims in published maps and institutional affiliations.

Open Access This article is licensed under a Creative Commons Attribution 4.0 International License, which permits use, sharing, adaptation, distribution and reproduction in any medium or format, as long as you give appropriate credit to the original author(s) and the source, provide a link to the Creative Commons license, and indicate if changes were made. The images or other third party material in this article are included in the article's Creative Commons license, unless indicated otherwise in a credit line to the material. If material is not included in the article's Creative Commons license and your intended use is not permitted by statutory regulation or exceeds the permitted use, you will need to obtain permission directly from the copyright holder. To view a copy of this license, visit http://creativecommons. org/licenses/by/4.0/.

(c) The Author(s) 2021 